\title{
Peroneal island flap for wound coverage in complex injuries of the lower extremity
}

This article was published in the following Dove Press journal:

Orthopedic Research and Reviews

23 January 2012

Number of times this article has been viewed

\author{
Akil Fazal' \\ Haroon-ur-Rashid' \\ Tahseen Cheema ${ }^{2}$ \\ 'Section of Orthopedics, Department \\ of Surgery, Aga Khan University, \\ Karachi, Pakistan; ${ }^{2}$ Department \\ of Orthopedics and Rehabilitation, \\ University of New Mexico, \\ Albuquerque, NM, USA
}

Background: Complex injuries of the lower extremity pose a therapeutic challenge owing to limited availability of local soft tissue for coverage. One option in this region is the pedicled fasciocutaneous flap based on perforators of the peroneal artery. In this case series, we present our experience of the peroneal island pedicled flap for reconstruction of lower extremity wounds.

Methods: Records of 18 cases of peroneal island flap admitted consecutively to the Section of Orthopedics at Aga Khan University Hospital from January 1996 to December of 2009 were studied and their outcomes determined.

Results: The most common indication for coverage was open wounds due to a road traffic accident $(n=10)$, followed by burns $(n=3)$. The most common area exposed was the lower third of the leg followed by the middle third. The tibia was exposed in 11 patients. The flaps ranged in size from $35 \mathrm{~cm}^{2}$ to over $200 \mathrm{~cm}^{2}$. In 13 patients, the flaps healed uneventfully, while in the remaining five there was partial flap necrosis. In four of the latter patients, the residual wound healed with conservative measures only, but the fifth patient required further surgery to achieve acceptable coverage.

Conclusion: The peroneal artery flap appears to be a simple, useful, and reliable flap in the armamentarium of the surgeon when planning soft tissue coverage of the lower extremity.

Keywords: leg injuries, surgical flaps, lower extremity

\section{Introduction}

Orthopedic injuries to the lower limb requiring soft tissue coverage present a challenging problem. Such injuries involve exposed bone and tendons and are therefore unsuitable for skin grafting. Owing to the minimal skin laxity in the leg, closure by primary intention is not a viable option. Moreover, healing by secondary intention entails a protracted period of repeated dressings, and usually results in a stiff and unstable scar that may frequently break down or hinder movement if close to a joint. ${ }^{1}$ Myocutaneous flaps are unavailable in the lower third of the leg, and in any case are associated with significant donor site morbidity. ${ }^{2}$ Free flaps on the other hand are technically difficult and involve long operative times.

The fasciocutaneous flap provides a useful method for dealing with skin coverage. First described by Ponten in 1981 as the "super flap", numerous fasciocutaneous flaps have subsequently been described in the lower limb. ${ }^{3}$ These flaps are raised to incorporate the deep fascia and are dependent for their survival on perforating blood vessels feeding the fascial plexus. ${ }^{4}$ In the lower limb, the sural artery, posterior tibial artery and supramalleolar flap have been well described. ${ }^{3}$ However, due to the nature
Section of Orthopedics, Department of Surgery, Aga Khan University, PO Box 3500, Stadium Road,

Karachi 74800, Pakistan

Tel +92 2I 4864350

Fax +92 214934294

Email masf2@yahoo.com 
of injury, these are not always available. Therefore, other options for flap coverage are needed.

The peroneal artery flap was first described by Shalaby in 1995 when he published a review of ten cases from Egypt. $^{5}$ This is a type B fasciocutaneous flap (Cormack and Lamberty) and is based on the posterolateral septocutaneous perforators of the peroneal artery. ${ }^{6}$ The number of septocutaneous perforators varies from three to five. These are distributed segmentally at $3-5 \mathrm{~cm}$ from the origin of the peroneal artery and have a diameter of $1-2 \mathrm{~mm} .^{7}$

The indications for use of the technique include an extensive skin defect with exposure of bone on tendon at any site from the knee to the foot, an extensive crushing injury of the soft tissues of the leg or foot, and extensive scar tissue of the leg or foot.

\section{Patients and methods}

A total of 18 patients underwent reconstruction of lower extremity wounds with the peroneal artery flap between January 1999 to December 2007. No patient was excluded. In patients presenting after acute injuries, the flap was not rotated in the initial surgery. First, the wounds were debrided, all contaminated and necrotic tissue was removed, and samples were obtained for culture and sensitivity testing. Initial cultures taken during the first debridement were negative in all cases. In the next session, once the wounds were clean, the flaps were elevated and rotated onto the defects.

\section{Surgical technique}

Prior to surgery, care was taken to localize the position of the perforators by transcutaneous Doppler probe. ${ }^{8}$ The flap is outlined in an elliptical shape over the course of the perforators as illustrated in Figure 1. Length of the flap should ideally be $2 \mathrm{~cm}$ more than the distance from the pivot perforator to the farthest margin of the defect. After marking the flap, subfascial dissection proceeds anteriorly up to the lateral intermuscular septum between the soleus and peroneus longus. The perforators are then exposed and mobilized by dissecting the septum. The pivot perforator is completely mobilized and the remaining perforators are ligated. The flap is then rotated around its axis by up to $180^{\circ}$ to cover the defect and sutured to its new position after confirming adequacy of perfusion. The donor site is then covered by a split thickness skin graft. Data were collected about each patient retrospectively. Statistical analysis was then carried out using SPSS software (SPSS, Inc, Chicago, IL). Outcome was measured as good (no necrosis), partial necrosis, or complete flap necrosis.

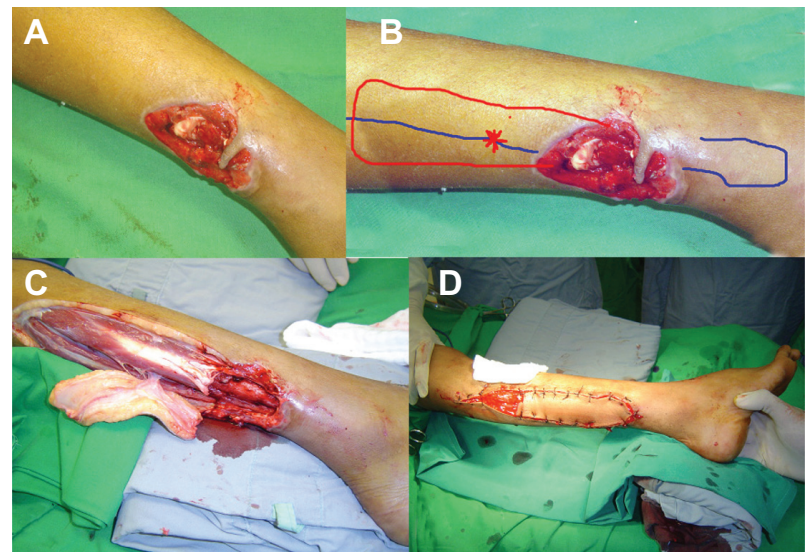

Figure I (A) Open wound over posterolateral aspect of the right leg, with exposed bone and tendon. (B) Skin markings of the fibula (blue) and the proposed flap margins (red) designed to cover the calf defect. Doppler used to locate peroneal artery perforator $\left(^{*}\right)$ which is the center of rotation. Distance from proximal margin of the flap to the perforator should be $2 \mathrm{~cm}$ more than the distance from the perforator to the distal margin of the wound. (C) Flap dissected and (D) rotated a full $180^{\circ}$ to cover the defect. The residual defect in the donor area is subsequently skin grafted.

\section{Results and discussion}

The peroneal artery flap has proved a worthy tool in the difficult problem of soft tissue coverage of the lower limb. As seen from our study population, it can be performed in adult patients as well as in small children. Most of our flaps were used for coverage of the middle and lower third of the leg as illustrated in Figure 2. Our experience has taught us that this is the most suitable site for the flap due to the close proximity of the septocutaneous perforators. The tibia was the most common structure exposed predictably due to the lack of soft tissue cover on the anterior aspect of the bone. As per surgical principles, aggressive debridement and negative cultures are essential prior to coverage with a fasciocutaneous flap, and this may explain the fact that we did not encounter any infection in our sample despite dealing with contaminated open fractures. The application of an external fixator in the same setting as rotating the flap did not adversely affect the outcome in anyway. However, the fixator should be applied first and then the flap performed. This avoids compromising vascularity of the flap by having to insert pins through it to achieve bony stability.

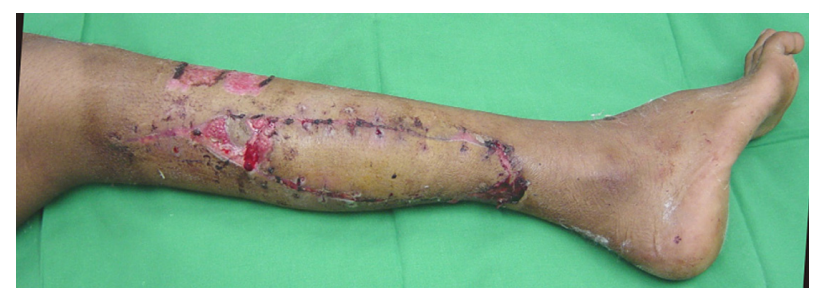

Figure 2 Outcome at 6 weeks showing successful coverage. 
Table I Patient characteristics

\begin{tabular}{|c|c|c|c|c|c|c|c|}
\hline Case & $\begin{array}{l}\text { Age } \\
\text { (years) }\end{array}$ & Gender & $\begin{array}{l}\text { Mechanism } \\
\text { of injury }\end{array}$ & Site of injury & $\begin{array}{l}\text { Dimensions } \\
\text { of flap }\left(\mathrm{cm}^{2}\right)\end{array}$ & $\begin{array}{l}\text { Outcome } \\
\text { of flap }\end{array}$ & $\begin{array}{l}\text { Further surgery } \\
\text { required }\end{array}$ \\
\hline I & 18 & $M$ & Sports injury & Middle I/3 & 120 & Good & No \\
\hline 2 & 29 & $M$ & RTA & Heel & 108 & Good & No \\
\hline 3 & 38 & $M$ & RTA & Distal I/3 & 72 & Good & No \\
\hline 4 & 4 & $M$ & RTA & Distal I/3 & 35 & Good & No \\
\hline 5 & 46 & $\mathrm{~F}$ & Burns & Proximal I/3 & 88 & Partial necrosis & No \\
\hline 6 & 44 & $M$ & RTA & Middle I/3 & 92 & Good & No \\
\hline 7 & 53 & $M$ & RTA & Distal I/3 & 200 & Good & No \\
\hline 8 & 28 & $M$ & Gunshot & Distal I/3 & 90 & Partial necrosis & No \\
\hline 9 & 40 & $M$ & Fall & Heel & 84 & Good & No \\
\hline 10 & 37 & $M$ & RTA & Proximal I/3 & 125 & Partial necrosis & No \\
\hline II & 18 & $\mathrm{~F}$ & RTA & Distal I/3 & 92 & Good & No \\
\hline 12 & 60 & $M$ & Burns & Middle I/3 & 88 & Partial necrosis & No \\
\hline 13 & 55 & $M$ & RTA & Middle I/3 & 68 & Good & No \\
\hline 14 & 47 & $M$ & RTA & Distal I/3 & 77 & Good & No \\
\hline 15 & 38 & $M$ & Gunshot & Middle I/3 & 112 & Good & No \\
\hline 16 & 36 & $M$ & RTA & Heel & 56 & Good & No \\
\hline 17 & 30 & $M$ & Burns & Distal I/3 & 84 & Partial necrosis & Yes, skin grafting \\
\hline 18 & 29 & $M$ & Gunshot & Middle I/3 & 108 & Good & No \\
\hline
\end{tabular}

Abbreviation: RTA, road traffic accident.

This flap is easy to learn and no special instruments are necessary. Preoperative localization with Doppler is helpful but not essential. However, it goes without saying that an excellent knowledge of anatomy is imperative. It does not involve sacrifice of one of the main leg arteries and is therefore quite useful in a trauma situation where the vascularity of the limb is jeopardized to begin with. It is a quick procedure and in most cases we finished the procedure within 45 minutes. This is of importance when dealing with a patient whose health may be compromised by other associated injuries.

The outcome in most patients was excellent as shown in Table 1. The few cases of partial necrosis were settled by conservative measures only. There was minimal donor site morbidity because all donor sites were successfully covered with split thickness skin grafts. This compares well with the reports of Shalaby and Yoshimura.,

Use of the peroneal island transfer has a number of advantages. Unlike the situation with cross-leg flaps, there is no need for immobilization of the involved leg. Therefore, patients with joint contractures that preclude use of a crossleg flap can have a peroneal island transfer. The pedicle can be long, so it is possible to transfer the island anywhere from slightly proximal to the knee joint to the foot. No vascular anastomosis is needed, so no special surgical instruments or techniques are needed. No functional impairment occurs, as is often the case with other musculocutaneous and muscle flaps when normal muscle has to be sacrificed.
Because the transferred subcutaneous adipose tissue is thin, there is no need for defatting. Therefore, fat necrosis is avoided. Because the transfer is made to a nearby site, the nature of the transferred skin is similar to that of the skin that was lost, and the transferred island may be quite large.

However, there are important limitations to the use of the transfer. It cannot be used in patients in whom circulation in the foot comes mainly from the peroneal artery, but this situation is uncommon. Also, variations in the location of the available cutaneous branches of the peroneal artery have to be taken into account. Nevertheless, the peroneal artery is a useful tool in the armamentarium of the reconstructive surgeon.

\section{Disclosure}

The authors report no conflicts of interest in this work.

\section{References}

1. Rohrich RJ. Current concepts in wound healing: update 2011. Plast Reconstr Surg. 2011;127 Suppl 1:1S-2S.

2. Hallock GG. Lower extremity muscle perforator flaps for lower extremity reconstruction. Plast Reconstr Surg. 2004;114(5):1123-1130.

3. Ponten B. The fasciocutaneous flap: its use in soft tissue defects of the lower leg. Br J Plast Surg. 1981;34(2):215-220.

4. Healy C, Tiernan E, Lamberty BG, Campbell RC. Rotation fasciocutaneous flap repair of lower limb defects. Plast Reconstr Surg. 1995;95(2):243-251.

5. Shalaby HA. The distally based peroneal island flap. Br J Plast Surg. 1995;48(1):23-26.

6. Cormack GC, Lamberty BG. A classification of fascio-cutaneous flaps according to their patterns of vascularisation. Br J Plast Surg. 1984;37(1):80-87. 
7. Yoshimura M, Imura S, Shimamura K, Yamauchi S, Nomura S. Peroneal flap for reconstruction in the extremity: preliminary report. Plast Reconstr Surg. 1984;74(3):402-409.

8. Hallock GG. Evaluation of fasciocutaneous perforators using color duplex imaging. Plast Reconstr Surg. 1994;94(5):644-651.
9. Yoshimura M, Shimada T, Imura S, Shimamura K, Yamauchi S. Peroneal island flap for skin defects in the lower extremity. J Bone Joint Surg Am. 1985;67(6):935-941.

Orthopedic Research and Reviews

Dovepress

\section{Publish your work in this journal}

Orthopedic Research and Reviews is an international, peer-reviewed, open access journal focusing on the patho-physiology of the musculoskeletal system, trauma, surgery and other corrective interventions to restore mobility and function. Advances in new technologies, materials, techniques and pharmacological agents are particularly welcome. The journal welcomes

Submit your manuscript here: http://www.dovepress.com/orthopedic-research-and-reviews-journal original research, clinical studies, reviews \& evaluations, expert opinion and commentary, case reports and extended reports. The manuscript management system is completely online and includes a very quick and fair peer-review system, which is all easy to use. Visit http://www.dovepress. com/testimonials.php to read real quotes from published authors. 